The Attitudes toward Pre-Exposure Prophylaxis (PrEP) Scale: Development and Validation

\author{
Rusi Jaspal $^{1}$, Bárbara Lopes ${ }^{2} \&$ Ismael Maatouk ${ }^{1,3}$
}

${ }^{1}$ Trinity House, De Montfort University, Leicester, UK

2 Center for Research in Neuropsychology and Cognitive and Behavioural Intervention (CINEICC); Faculdade de Psicologia e de Ciências da Educação, Universidade de Coimbra, Rua do Colégio Novo, 3001-802, Coimbra, Portugal. Webpage: https://cineicc.uc.pt/

${ }^{3}$ Clemenceau Medical Center Affiliated with Johns Hopkins International, Beirut, Lebanon

Jaspal, R., Lopes, B. \& Maatouk, I. (in press). The Attitudes toward Pre-Exposure Prophylaxis (PrEP) Scale: Development and Validation. Journal of HIV/AIDS \& Social Services. 
The Attitudes toward Pre-Exposure Prophylaxis (PrEP) Scale: Development and Validation

\begin{abstract}
PrEP is a novel, clinically effective biomedical HIV prevention tool but it has not met with widespread public acceptance. In this article, the results of a study designed to develop a scale for measuring attitudes toward PrEP is presented. The psychometric properties of the scale are described for use in both the general population and in patient samples. 222 university students completed the Attitudes toward PrEP Scale (APS) and additional measures of attitudes toward gay men, Black Africans and condom use. The APS comprised 3 factors (Attitudes toward the Science of PrEP, Perception of Sexual Health Risks of PrEP, and Perception of Dangerous Effects of PrEP) which explained $49.31 \%$ of the variance. The 14 -item APS had a good internal consistency, $\alpha=.72$, and satisfactory concurrent validity with measures of condom use, and attitudes toward social groups associated with PrEP. Additional studies in other non-student samples are required to assess the external validity of the scale.
\end{abstract}

\title{
Keywords
}

PrEP, HIV, sexual health, attitudes; gay men 


\section{The Attitudes toward Pre-Exposure Prophylaxis (PrEP) Scale: Development and Validation}

\section{INTRODUCTION}

Health conditions which are socially represented as being specific to marginalized communities often become de-prioritized in public and policy debates. Policies designed to benefit stigmatised social groups tend to receive lower support and to be allocated fewer resources than policies that serve more positively regarded, advantaged social groups (Schneider \& Sidney, 2009). HIV is an important global public health issue - since the clinical observations of HIV/AIDS in 1981, 78 million people have been infected with HIV and 35 million have died of AIDS globally (UNAIDS, 2017). Yet, public opinion of HIV and the tools used to prevent it tend to be negative as the disease is perceived as affecting only marginalized populations, such as gay men and Black Africans. Pre-exposure prophylaxis (PrEP) is a novel, clinically effective biomedical approach to preventing HIV but it has not met with widespread public acceptance. Although there has been some qualitative research into patient acceptability of PrEP (e.g. Jaspal \& Daramilas, 2016), there has none focussing on public acceptability of PrEP in the UK. Public opinion can decisively shape policy and practice (Burnstein, 2003). In this article, the results of a study designed to develop a novel scale for measuring attitudes toward PrEP is presented. The psychometric properties of the scale are described for use in both the general population and in patient samples.

Prevention is the most effective tool against HIV. Although condoms constitute an effective prevention option, they are not used consistently in all populations at risk, which has led to continued HIV incidence (Jaspal, 2018). 
Accordingly, in recent years, PrEP, has emerged as a significant biomedical approach to HIV prevention. In 2012, Emtricitabine/Tenofovir Disoproxil Fumarate (sold under the brand name Truvada $\left.{ }^{\circledR}\right)$ became the first drug to be approved by the US Food and Drug Administration (FDA) for use as PrEP. In several clinical trials, PrEP has repeatedly been shown to reduce the risk of HIV transmission by up to $86 \%$ in men who have sex with men, a group at high risk of HIV (McCormack et al., 2016). However, PrEP is not yet available on the National Health Service (NHS) in all parts of the United Kingdom. This can be attributed in part to the concerns raised in both media and public discourses concerning the risks of PrEP on both individual and public health, as well as the costs (Jaspal \& Nerlich, 2017).

Social psychology research has demonstrated that human beings tend to 'other' disease and to perceive it as affecting only outgroups (Joffe, 2007). HIV is thus often viewed as affecting distant and dissimilar outgroups. Furthermore, there is empirical evidence of ingroup favoritism in the context of resource allocation people tend to favour their own groups or groups that are close to their ingroup when resources are allocated and, accordingly, oppose outgroup beneficiaries of resources (Harvey \& Bourhis, 2012). This has also been observed in a study of funding for PrEP (Calabrese et al., 2016). Furthermore, there has been some research into public and media perspectives on PrEP in the UK. Jaspal and Nerlich (2017) found that stigmatizing group-level stereotypes of gay men were drawn upon both to affirm and repudiate PrEP. Some media reports questioned why 'we' (the heterosexual ingroup) should support an HIV prevention tool for 'them' (the gay outgroup). In a US study of how public attitudes toward PrEP vary according to the social group presented as benefitting from it (Calabrese et al., 2016), participants manifested less support for PrEP funding policies when PrEP was represented as benefitting gay men and Black 
gay man, suggesting that prejudice toward these stigmatized groups causes decreased support for the prevention tool. However, unlike the US context in which Calabrese et al.'s study was conducted, the state-funded NHS is the principal healthcare provider in the United Kingdom and, thus, attitudes in the United Kingdom general public will play a significant role in determining PrEP policy. A robust scale is needed to measure the public's attitudes toward PrEP.

\section{METHOD}

\section{Participants}

Two hundred and twenty-two undergraduate students were invited to participate in a study on attitudes toward PrEP in exchange for course credits. Participants were aged between 18 and $37(M=23.34 \& S D=2.09)$. One hundred and thirty $(59 \%)$ were female and 90 (41\%) male. All of the participants self-identified as heterosexual. The majority of the 222 participants was either British Indian, $N=60(27 \%)$, or White British, $N=50(23 \%)$. Thirty-two individuals described themselves as Black African $(14.4 \%) ; 22(9.9 \%)$ as White European; $14(6.3 \%)$ as Mixed Heritage; $11(5 \%)$ as Chinese; $11(5 \%)$ as Pakistani; $16(7.2 \%)$ as 'Other'; 4 (1.8\%) as Black Caribbean; and $2(.9 \%)$ as Bangladeshi (see table 1 for full descriptives).

\section{Measures}

The Attitudes toward PrEP Scale (APS) (see Table 1) was created on the basis of qualitative interview research into PrEP attitudes (Jaspal \& Daramilas, 2016). To increase ecological validity, participants were first presented with vignettes describing distinct beneficiaries of PrEP (gender: male vs. female; ethnicity: Black vs. White, and sexual orientation: heterosexual vs. gay). This was important because research 
shows that people form their attitudes toward PrEP on the basis of social groups associated with it (Calabrese et al., 2016; Jaspal, 2018). Apart from the identity configuration, all of the 6 vignettes were identical in content and included the following text:

\begin{abstract}
[Ashley/Michael/Shaniqua/ Kgalema] is a 22-year-old [English/African] [woman/gay man/man]. [She/ He] is HIV-negative and wants to avoid getting HIV. [She/ He] is thinking of taking pre-exposure prophylaxis (PrEP), a daily pill that can protect [her/him] against HIV even if [she/he] has sex with an HIV-positive [man/woman].
\end{abstract}

Then participants had to respond to 14 items that measured positive and negative attitudes toward PrEP while keeping in mind the vignette. Participants indicated their level of agreement with the statements on a Likert response scale ranging from 1=Strongly Disagree to 5=Strongly Agree. Examples of items are "PrEP is an exciting breakthrough in medical science" (positive) and "PrEP will probably have serious side effects" (negative). The scale can be adapted to specific groups as PrEP users, such as gay men, Black Africans, and women. The negative items 3,4,5,8,9,10 and 11 were reversed to produce a total score of attitudes toward PrEP.

The Attitudes toward Gay People Scale (Herek, 1997) was used to measure participants attitudes toward gay men. The scale consists of 10 items and had a good internal reliability, $\alpha=.80$.

The Generalized Group Attitude Scale (Duckitt \& Mputhing, 1998) was adapted to measure attitudes toward Black Africans. The scale consists of 8 items and had a good internal reliability, $\alpha=.74$. 
The Sexual Risks Scale was used to measure attitudes toward condoms. The scale consists of 13 items and had an excellent internal reliability, $\alpha=.89$.

\section{RESULTS}

\section{Descriptives}

The total score of Attitudes toward PrEP presented a mean of 44.66 and a $S D=6.49$, mimimum value $=25$, maximum value $=61$. Attitudes toward PrEP presented acceptable values $<1$ for Skewness $=.-25$ and for Kurtosis=. 27. A KS test showed that the distribution of Attitudes toward PrEP was normal $D(222)=1.16, p=.14$. An independent samples t-test also showed that there was no statistically significant difference between males' $(M=44.41, S D=5.91)$ and females' $(M=44.86, S D=6.97)$ attitudes toward PrEP, $t(215)=.50, p=.62$.

\section{Factor analysis}

The structure of the Attitudes toward PrEP scale was explored as follows. All interitem correlations were positive and significant at the 0.05 level. All items were included in subsequent analyses. The Cronbach alpha for the scale was .72 showing good internal consistency of the items composing the scale.

A principal components analysis with varimax rotation was carried out with a cut of 0.4 for the inclusion of a variable in the interpretation of a factor. The KayserMeyer-Olkin measure showed a value of .78 demonstrating good sample adequacy for the analysis. The Bartlett's test of sphericity was also statistically significant $\left[\chi^{2}(91)=638.331, p<.001\right]$.

This analysis produced a solution with three factors having eigenvalues greater than one. These three factors accounted for $49.31 \%$ of the variance in the 
factor space ( Factor 1 accounted for $25.69 \%$ of the variance, Factor 2 accounted for $15.34 \%$ of the variance and Factor 3 for $8.28 \%$ of the variance, see Table 2).

Factor 1 consisted of items 1, 2, 6,7,13 and 14. These items all tap into "Attitudes toward the Science of PrEP", such as the perception of PrEP as a medical breakthrough. Factor 2 consisted of items 9,10,11,12 and these items contribute to a factor of "Perception of Sexual Health Risks of PrEP" which reflects concerns that PrEP users will cease to use condoms and take more sexual risks. Factor 3 brought together those items relating to what might be called "Perception of Dangerous Effects of PrEP", reflecting concerns about adverse side-effects associated with PrEP use (items 3,4,5).

\section{Internal consistency of the scale}

All items of the APS have inter-item correlations equal to and above .30 (see Table 3) The Cronbach alpha for the scale was $.72(n=14)$. The Cronbach alpha scores for the dimensions of the Attitudes toward PrEP Scale were acceptable given the number of items of each sub-scale: "Attitudes toward the Science of PrEP" (n=6) $\alpha=.70$; "Perception of Sexual Health Risks of PrEP" (n=4) $\alpha=-.69$ and "Perception of Dangerous Effects of PrEP" $(n=3) \alpha=.59$.

Correlations between the three dimensions of the Attitudes toward PrEP Scale were all statistically significant. "Attitudes toward the Science of PrEP" correlates statistically significantly and negatively with "Perception of Sexual Health Risks of PrEP" $r(222)=-.26, p<.001$, meaning that the more positive one's attitudes toward the science of PrEP, the less people perceive sexual health risks to be associated with PrEP use. Furthermore, "Attitudes toward the Science of PrEP" also correlates negatively with "Perception of Dangerous Effects of PrEP", $r(222)=-.18$, 
$p=.007$, suggesting that the more positive one's attitudes toward the science of PrEP, the less dangerous one perceives the effects of PrEP. "Perception of Dangerous Effects of PrEP" also correlates positively with "Perception of Sexual Health Risks of PrEP", $r(222)=.25, p<.001$. This suggests that the more dangerous one perceives the effects of PrEP use to be, the more one perceives sexual health risks to be associated with PrEP use.

\section{Concurrent Validity}

Spearman Rho's correlations were performed since the variables of attitudes toward gay men and Black Africans were not normally distributed so a more conservative approach was taken. Results showed positive and moderate correlations between attitudes toward PrEP and attitudes toward gay men $(r=.29, p<.001)$, attitudes toward Black Africans $(r=.25, p<.001)$, and less so with attitudes toward condoms $(r=.18$, $p=.008)$. This means that the more people report positive attitudes toward PrEP, the more positive attitudes their attitudes toward gay men, Black Africans and condoms. The three dimensions of the Attitudes toward PrEP Scale also correlate with attitudes toward gays and Black Africans (see table 3), suggesting concurrent validity of the scale and its dimensions with other measures of attitudes of social groups associated with PrEP (see table 4).

\section{CONCLUSION}

The 14-item APS is a relatively short questionnaire, which can be administered to both the general public and patient samples. Patient attitudes are key to clinical effectiveness, while public attitudes shape policy responses. To our knowledge, this is the first measure to assess attitudes toward PrEP directly and in a multi-faceted 
manner, tapping into three significant factors, namely attitudes toward the science of PrEP, the perception of sexual health risks among PrEP users, and the perception of dangerous effects associated with PrEP use. The APS appears to have satisfactory reliability and validity for assessing PrEP attitudes, and correlates with relevant psychosocial constructs, namely attitudes toward gay men and Black Africans, who are associated with an increased HIV risk, and with attitudes toward condoms, another HIV prevention method. The scale can be adapted to measure PrEP use in specific groups. It is noteworthy that this is a small-scale study, albeit with a diverse sample, and, thus, it is hoped that the scale will be validated in other population samples.

\section{REFERENCES}

Burnstein, P. (2003). The impact of public opinion on public policy: a review and an agenda. Political Research Quarterly, 56(1), 29-40.

Calabrese, S.K., Underhill, K., Earnshaw, V.A., et al. (2016). Framing HIV preexposure prophylaxis (PrEP) for the general public: how inclusive messaging may prevent prejudice from diminishing public support. AIDS \& Behavior, 20(7), 1499513.

Duckitt, J. \& Mphuthing, T. (1998). Group identification and intergroup attitudes: a longitudinal analysis in South Africa. Journal of Personality and Social Psychology, $74(1), 80-5$. 
Harvey, S. \& Bourhis, R.Y. (2012). Discrimination in wealth and power intergroup structures. Group Processes \& Intergroup Relations, 15(1), 21-38.

Herek, G.M. (1994). Assessing heterosexuals' attitudes toward lesbians and gay men: A review of empirical research with the ATLG scale. In B. Greene, \& G.M. Herek (Eds.) Lesbian and gay psychology: Theory, research, and clinical applications (pp. 206-228). Thousand Oaks, CA: Sage Publications.

Jaspal, R. (2018). Enhancing Sexual Health, Self-Identity and Wellbeing among Men Who Have Sex With Men: A Guide for Practitioners. London: Jessica Kingsley Publishers.

Jaspal, R. \& Daramilas, C. (2016). Perceptions of pre-exposure prophylaxis (PrEP) among HIV-negative and HIV-positive men who have sex with men. Cogent Medicine. 3: 1256850. https://doi.org/10.1080/2331205X.2016.1256850

Jaspal, R. \& Nerlich, B. (2017) Polarised Reporting about HIV Prevention: Social Representations of Pre-Exposure Prophylaxis (PrEP) in the UK Press. Health, 21(5), $478-497$

Joffe, H. (2007) Identity, self-control, and risk. In G. Moloney \& I. Walker (eds) Social Representations and Identity. New York: Palgrave Macmillan.

McCormack, S., Dunn, D.T., Desai, M., Dolling, D.I., Gafos, M., Gilson, R., et al. (2016). Pre-exposure prophylaxis to prevent the acquisition of HIV-1 infection 
(PROUD): effectiveness results from the pilot phase 1 of a pragmatic open-label randomised trial. The Lancet, 387, 53-60

Schneider, A., Sidney, M. (2009). What is next for policy design and social construction theory? Policy Studies Journal, 37(1), 103-19.

UNAIDS, (2017) Ending AIDS: Progress towards the 90-90-90 Targets. Available at http://www.unaids.org/sites/default/files/media_asset/Global_AIDS_update_2017_en. pdf

Accessed

13

September

2017 
Table 1. Socio-demographic characteristics and descriptives for study participants

\begin{tabular}{|c|c|c|c|c|c|c|c|c|c|c|}
\hline Variables & $M$ & $S D$ & Minimum & Maximum & & & & & & \\
\hline Attitudes toward PrEP & 44.67 & 6.49 & 25 & 61 & & & & & & \\
\hline Attitudes toward gay men & 38.26 & 10.43 & 8 & 53 & & & & & & \\
\hline Attitudes toward Black Africans & 33.90 & 5.40 & 4 & 40 & & & & & & \\
\hline Attitudes toward condoms & 42.15 & 11.48 & 5 & 65 & & & & & & \\
\hline \multicolumn{11}{|l|}{ Socio-demographic variables } \\
\hline Age & 23.34 & 2.09 & 18 & 37 & & & & & & \\
\hline \multirow[t]{2}{*}{ Ethnicity } & $\begin{array}{l}\text { British } \\
\text { Indian }\end{array}$ & White British & $\begin{array}{l}\text { Black } \\
\text { African }\end{array}$ & $\begin{array}{l}\text { White } \\
\text { European }\end{array}$ & $\begin{array}{l}\text { Mixed } \\
\text { Heritage }\end{array}$ & Chinese & Pakistani & Other & $\begin{array}{l}\text { Black } \\
\text { Caribbe } \\
\text { an }\end{array}$ & $\begin{array}{l}\text { Banglades } \\
h i\end{array}$ \\
\hline & $60(27 \%)$ & $50(23 \%)$ & $32(14.4 \%)$ & $22(9.9 \%)$ & $14(6.3 \%)$ & $11(5 \%)$ & $11(5 \%)$ & $\begin{array}{l}16 \\
(7.2 \%)\end{array}$ & $\begin{array}{l}4 \\
(1.8 \%)\end{array}$ & $2(.9 \%)$ \\
\hline \multirow[t]{2}{*}{ Religion } & Muslim & Christians & Hindus & Sikhs & Budhists & Other & & & & \\
\hline & $69(31 \%)$ & $51(23 \%)$ & $15(6.7 \%)$ & $10(4.5 \%)$ & $5(2 \%)$ & $3(1.3 \%)$ & & & & \\
\hline \multirow[t]{2}{*}{ Civil relationship status } & Single & $\begin{array}{l}\text { Monogamous } \\
\text { relationship }\end{array}$ & Married & $\begin{array}{l}\text { Open } \\
\text { relationship }\end{array}$ & $\begin{array}{l}\text { Civil } \\
\text { relationship }\end{array}$ & $\begin{array}{l}\text { Another } \\
\text { type of } \\
\text { relationship }\end{array}$ & & & & \\
\hline & $133(60 \%)$ & $70(30 \%)$ & $10(4.5 \%)$ & $6(7 \%)$ & $2(.9 \%)$ & $1(.6 \%)$ & & & & \\
\hline \multirow[t]{2}{*}{ Currently Sexually active } & Yes & No & & & & & & & & \\
\hline & $126(57 \%)$ & $95(40 \%)$ & & & & & & & & \\
\hline \multirow[t]{2}{*}{ Gender } & Females & Males & Other & & & & & & & \\
\hline & $130(59 \%)$ & $90(40 \%)$ & $2(.9 \%)$ & & & & & & & \\
\hline Taking contraceptive pill & $\begin{array}{l}\text { Yes } \\
27(20 \%)\end{array}$ & $\begin{array}{l}\text { No } \\
110(80 \%)\end{array}$ & & & & & & & & \\
\hline
\end{tabular}


Table 2. Factor Loadings of the Attitudes toward PrEP Scale

\begin{tabular}{|c|c|c|c|}
\hline Items of the Attitudes toward PrEP Scale & Factor 1 & Factor 2 & Factor 3 \\
\hline 1. $[$ Trarget group $]$ should take PrEP. & .60 & & \\
\hline 2. PrEP is likely to work. & .54 & & \\
\hline 3. PrEP will probably have serious side effects. (R) & & & .69 \\
\hline 4. [Target group] ought to be worried about PrEP. (R) & & & .74 \\
\hline 5. PrEP will be too expensive for general use. & & & .63 \\
\hline 6. The NHS should fund PrEP. & .66 & & \\
\hline 7. PrEP is an exciting breakthrough in medical science. & .73 & & \\
\hline 8. PrEP is more dangerous than good $(\mathrm{R})$. & .41 & & \\
\hline 9. PrEP will encourage [target group] to take sexual risks. (R) & & .64 & \\
\hline 10. If [target group] takes PrEP, she will probably stop using condoms altogether. (R) & & .77 & \\
\hline 11. If [target group] takes PrEP, she will probably have sex with lots of different men. (R) & & .79 & \\
\hline 12. [Target group] will probably take PrEP consistently. & & .58 & \\
\hline 13.The researchers who developed PrEP are to be admired. & .70 & & \\
\hline 14. I would like to learn more about this field of medical research. & .52 & & \\
\hline Eigenvalue & 3.6 & 2.2 & 1.2 \\
\hline Variance (\%) & $25.69 \%$ & $15.34 \%$ & $8.28 \%$ \\
\hline
\end{tabular}


Table 3. Inter-item Correlations of the Attitudes toward PrEP scale items

\begin{tabular}{llll}
\hline & Dimensions & Inter-item correlations & Cronbach alpha without item \\
\hline Item 1 & Attitudes toward the Science of PrEP & .42 & .57 \\
Item 2 & & .46 & .58 \\
Item 6 & .42 & .57 \\
Item 7 & .46 & .57 \\
Item 8 & & .41 & .58 \\
Item 13 & .46 & .57 \\
Item 14 & & .43 & .62 \\
Item 9 & Perception of Sexual Health Risks of PrEP & .39 & .58 \\
Item 10 & & .30 & .62 \\
Item 11 & & .37 & .71 \\
Item 12 & Perception of Dangerous Effects of PrEP & .30 & .64 \\
Item 3 & .30 & .60 \\
Item 4 & .40 & .58 \\
Item 5 & & .30 & .62 \\
\hline
\end{tabular}


Table 4. Correlations between Attitudes toward PrEP scale and its dimensions with attitudes toward gay men, Black Africans, and condoms

\begin{tabular}{|c|c|c|c|c|c|c|c|}
\hline Variables & 1 & 2 & 3 & 4 & 5 & 6 & 7 \\
\hline Attitudes toward PrEP score & & $.84 * *$ & $-.60^{* *}$ & $-.57 * *$ & $.29 * *$ & $.18 * *$ & $.25 * *$ \\
\hline Dimension of Attitudes toward the Science of PrEP & $.84 * *$ & & $-.26 * *$ & $-.18 * *$ & $.23 * *$ & .11 & $.26 * *$ \\
\hline Dimension of Perception of Sexual Health Risks of PrEP & $-.60 * *$ & $-.26 * *$ & & $.25 * *$ & -.10 & -.09 & $-.14^{*}$ \\
\hline Dimension of Perception of Dangerous Effects of PrEP & $-.57 * *$ & $-.18 * *$ & $.25 * *$ & & $-.25 * *$ & $-.24 * *$ & -.11 \\
\hline Attitudes toward gay men & $.29 * *$ & $.23 * *$ & -.10 & $-.25 * *$ & & $.27 * *$ & $.33 * *$ \\
\hline Attitudes toward condoms & $.18 * *$ & .11 & -.09 & $-.24 * *$ & $.27 * *$ & & .10 \\
\hline Attitudes toward Black Africans & $.25 * *$ & $.26 * *$ & $-.14 *$ & -.11 & $.33 * *$ & .10 & \\
\hline
\end{tabular}

$* p<.050$

$* * p<.005$ 